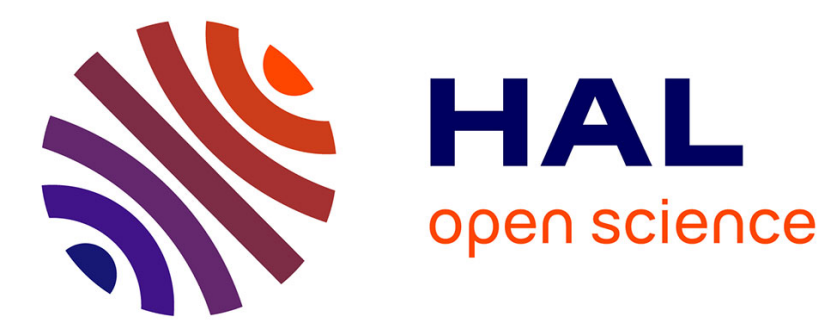

\title{
Manufacturing of complex diamond-based composite structures via laser powder-bed fusion
}

Loic Constantin, Nada Kraiem, Zhipeng Wu, Bai Cui, Jean-Luc Battaglia, Christian Garnier, Jean-François Silvain, Yong Feng Lu

\section{- To cite this version:}

Loic Constantin, Nada Kraiem, Zhipeng Wu, Bai Cui, Jean-Luc Battaglia, et al.. Manufacturing of complex diamond-based composite structures via laser powder-bed fusion. Additive Manufacturing, 2021, 40, 101927 (9 p.). 10.1016/j.addma.2021.101927 . hal-03498813

\section{HAL Id: hal-03498813 https://hal.science/hal-03498813}

Submitted on 10 Jan 2022

HAL is a multi-disciplinary open access archive for the deposit and dissemination of scientific research documents, whether they are published or not. The documents may come from teaching and research institutions in France or abroad, or from public or private research centers.
L'archive ouverte pluridisciplinaire HAL, est destinée au dépôt et à la diffusion de documents scientifiques de niveau recherche, publiés ou non, émanant des établissements d'enseignement et de recherche français ou étrangers, des laboratoires publics ou privés. 


\section{Manufacturing of Complex Diamond-Based Composite Structures}

\section{via Laser Powder-Bed Fusion}

Loic Constantin, ${ }^{1,2, *}$, Nada Kraiem, ${ }^{1,2, *}$, Zhipeng Wu, ${ }^{1, *}$ Bai Cui, ${ }^{3,}$ Jean-Luc Battaglia, ${ }^{4,}$ Christian Garnier, ${ }^{5,}$ Jean-François Silvain, ${ }^{1,2,} *$ and, Yong Feng Lu, ${ }^{1,} *$

${ }^{1}$ Department of Electrical and Computer Engineering, University of Nebraska-Lincoln, Lincoln, NE, 68588, USA.

${ }^{2}$ CNRS, Univ. Bordeaux, Bordeaux I.N.P., ICMCB, UMR 5026, F-33608 Pessac, France.

${ }^{3}$ Department of Mechanical and Materials Engineering, University of Nebraska-Lincoln, Lincoln, NE 68588-0526, USA.

${ }^{4}$ CNRS, University of Bordeaux, I2M, UMR 5295, F-33400 Talence, France

${ }^{5}$ LGP-ENIT-INPT, M2SP team, University of Toulouse, F-65016 Tarbes, France

Abstract: Manufacturing complex metal matrix composite (MMC) structures by laser powderbed fusion (LPBF) could unleash their full potential but is difficult due to the presence of reinforcement. Unmelted particles negatively affect the pool dynamics, cause critical spatter ejections, and form printing defects. In this work, by taking copper $(\mathrm{Cu}) /$ diamond (D) composite as an example for its prospective thermal management applications and machinability limitations; we discovered that adding steps to LPBF enables the fabrication of high-quality materials and structures. We demonstrated that adding a recoating step improves the composite quality compared to structures manufactured by conventional LPBF. Adding a remelting step enabled further improvement by limiting the generation of spatter and printing defects, leading to $3 \mathrm{D}$ laser print dense (97\%), highly thermally conductive (349 W/m.K) and complex Cu/5 vol.\% D structures. 
Therefore, pursuing research into nonconventional LPBF could open new avenues for manufacturing MMCs.

Keywords: additive manufacturing, copper, diamond, selective laser melting, metal matrix composites 


\section{Introduction}

Laser powder-bed fusion (LPBF) provides a unique way of fabricating intricate designs that are not possible by conventional manufacturing methods, thereby revolutionizing the biomedical, defense, and aerospace industries [1]. On the other hand, metal matrix composites (MMCs) are among the most promising materials for advanced applications. The combination of a metal matrix with a reinforcement enables the formation of materials with enhanced and tailored mechanical, thermal, and electrical properties [2]. To date, MMCs are manufactured by solid (i.e., powder metallurgy) and liquid state methods (i.e., stir casting, squeeze casting), producing simple designs, thus restricting their full capabilities [3]. Copper $(\mathrm{Cu}) /$ diamond (D) composite is an excellent example of an MMC, where adding D particles tailors the Cu's coefficient of thermal expansion (CTE) while enhancing its thermal conductivity (TC) [4]. This MMC is one of the most advanced materials for thermal management applications, yet its shape remains simple due to complexities of machining D-based materials. Therefore, merging the abilities of LPBF to create sophisticated designs with the outstanding properties of MMCs can unleash the full capability of the $\mathrm{Cu} / \mathrm{D}$ materials and remodel their applications [5,6]. Nonetheless, the LPBF of $\mathrm{Cu} / \mathrm{D}$ composite remains challenging and less explored due to the intricacy of laser three-dimensional (3D) printing of micro composites, the high thermal conductivity of $\mathrm{Cu}$ and $\mathrm{D}$, and the low optical absorption of $\mathrm{Cu}$ in the infrared (IR) domain.

The difficulties encountered in the 3D printing of micro composites arise from the significant size of the solid reinforcement, which plays a critical role in the densification behavior. L. Xi et al. showed that finer reinforcements allow manufacturing denser composites compared to a coarser reinforcement [7]. Micrometric particles significantly alter the transit molten pool dynamics, rheology, and flowability, leading to porous parts' formation [8-10]. Consequently, different 
approaches were developed to 3D laser print MMCs via LPBF. The first approach involves creating a composite powder containing a metal matrix and a nano reinforcement to form a homogenous mixture at the microscale, allowing 3D printing of dense MMCs [11-14]. However, this method limits the type of MMCs to nanocomposites and cannot be generalized for $\mathrm{Cu} / \mathrm{D}$ materials. The second approach consists of the in-situ formation of the reinforcement [15-18]. This technique enables the manufacturing of dense MMCs with micro/nano-sized reinforcement; but once again, a limited number of reinforcements can be formed during LPBF.

Furthermore, $\mathrm{Cu}$ is one of the most challenging metals for 3D laser printing due to its low optical absorption in the near-IR and its high TC. In other words, the laser energy is either reflected or quickly dissipated when striking the $\mathrm{Cu}$ powder [19]. SD. Jadlhav, et al. reported the LPBF of dense (99\%) and highly thermally conductive $\mathrm{Cu}$ parts $(336 \mathrm{~W} / \mathrm{m} . \mathrm{K})$ using a high-power laser $(800$ W) [20]. However, they also noticed damage to the laser optics caused by the high IR reflectivity of $\mathrm{Cu}$. Later, they showed that adding carbon (C) nanoparticles into the $\mathrm{Cu}$ matrix enhanced the laser absorption; but the $\mathrm{TC}$ of the $\mathrm{Cu} / \mathrm{C}$ composite was severely degraded (164 W/m.K) [21]. Alternatively, the LBPF of pure $\mathrm{Cu}$ with low laser power (200 to $600 \mathrm{~W}$ ) results in decreased part density (83 to $96 \%$ ), as reported by others [22-24]. For these reasons, extensive research has focused on $\mathrm{Cu}$ alloys, which have much higher absorption in the IR domain. Among them, $\mathrm{Cu}-$ chromium (Cr) appears to be one of the most promising alloys because of its high TC $(340 \mathrm{~W} / \mathrm{m} . \mathrm{K})$ and improved laser absorption compared to $\mathrm{Cu}$ [25]. Nevertheless, the TC of the as-printed $\mathrm{Cu}-\mathrm{Cr}$ alloys is low $(<115 \mathrm{~W} / \mathrm{m} . \mathrm{K})$ due to the dissolution of the $\mathrm{Cr}$ phase in the $\mathrm{Cu}$ matrix [26,27].

Here, we overcame these challenges and successfully 3D print dense, complex, and highly conductive $\mathrm{Cu} / 5$ vol.\% D composites by implementing different printing strategies (i.e., recoating and remelting). The printing parameters (e.g., laser power, scan speed, hatch distance, etc.) are 
well known to play a vital role in the quality and properties of the LPBF part'. Analogously, the printing strategy has an influence on the material characteristics but has been less explored. In other words, optimizing the printing parameters, along with the strategy, could open new ways to additively manufacture a broader range of MMCs. In our approach, the relative density of the $\mathrm{Cu} / \mathrm{D}$ composite is increased from 88 to $92 \%$ by first adjusting the printing parameters and subsequently adding a recoating step, allowing the composite's TC to be increased from 236 to $327 \mathrm{~W} / \mathrm{m} . \mathrm{K}$. Next, the relative density was further improved to $97 \%$ by implementing a remelting step, leading to the manufacturing of highly conductive composites with a TC of $349 \mathrm{~W} / \mathrm{m}$.K. Finally, the fabrication of sophisticated $\mathrm{Cu} / \mathrm{D}$ designs was demonstrated with potential thermal management applications.

\section{Material and methods}

\subsection{Preparation of titanium (Ti)-based interphase on diamond particles.}

Diamond particles (Eastwind Diamond Abrasives, mean diameter $25 \mu \mathrm{m}$ ) were coated using a graded $\mathrm{TiO}_{2}$-TiC molten salt process. For that, D particles were mixed with metallic Ti powders $(99.5 \%$, mean diameter $40 \mu \mathrm{m})$ and potassium chloride $(\mathrm{KCl})$ salt (Sigma-Aldrich $99 \%)$ at a molar ratio of $\mathrm{KCl}: \mathrm{C}: \mathrm{Ti}=0.64: 1: 0.04$. The mixture was then placed in an alumina crucible and heated in a tube oven filled with argon (Ar) at $850^{\circ} \mathrm{C}$ for $4 \mathrm{~h}$. After cooling down, the crucible was immersed in boiling distilled water to dissolve the salt. The coated $\mathrm{D}$ particles were then retrieved by filtration and air-dried in an oven at $60^{\circ} \mathrm{C}$ for $12 \mathrm{~h}$. SEM micrographs of the original and coated -D are presented in Fig. S1a - b. The coating thickness is estimated to be about 600 to $700 \mathrm{~nm}$ based on a previous study [6]. More details of the molten salt coating can be found elsewhere [28].

\subsection{Laser powder-bed fusion of $\mathrm{Cu} / \mathrm{D}$ composites.}


Coated -D particles were mixed with spherical Cu powder (US Nano, $\mathrm{Cu} 99.5 \%$, mean diameter $45 \mu \mathrm{m})$ at a volume percentage of $5 \%$ (Fig. S1c $-\mathbf{f})$. The laser powder-bed fusion was carried out using the $\mathrm{SLM}^{\circledR} 125$ 3D printer from SLM Solutions. The printer is equipped with a continuous wave $(\mathrm{CW})$ fiber laser (IPG photonics, YLM, Yb: YAG, $\lambda=1070 \mathrm{~nm}$ ) with a maximum output power of $400 \mathrm{~W}$. The laser spot was focused to a diameter of $70 \mu \mathrm{m}$ on the powder-bed surface. The printing chamber was filled with $\operatorname{Ar}$ (99.9\%, Matheson) to reduce the oxygen level to about $0.10 \%$. A constant pressure of 18 mbar was maintained in the chamber during all experiments. A stripe laser scan strategy was used for all prints. The laser power and layer thickness were kept constant at $400 \mathrm{~W}$ and $0.03 \mathrm{~mm}$ throughout the study. First, the single-melting strategy was investigated for scan speeds and hatches ranging from 100 to $600 \mathrm{~mm} / \mathrm{s}$ and 0.03 to $0.20 \mathrm{~mm}$, respectively. Next, the recoating and remelting strategies were employed at scan speeds and hatch distances ranging from 200 to $450 \mathrm{~mm} / \mathrm{s}$ and 0.06 to $0.12 \mathrm{~mm}$, respectively. The energy density $\left(\mathrm{J} / \mathrm{mm}^{3}\right)$ was calculated with the following equation:

$$
E=\frac{P}{L T \times h \times s},
$$

where $P$ is the laser power (W), $L T$ is the layer thickness $(\mathrm{mm}), h$ is the hatch distance (mm), and $s$ is the scan speed $(\mathrm{mm} / \mathrm{s})$. The structures designed using SOLIDWORKS ${ }^{\circledR}$ were uploaded to the Materialise Magics software for parameter assignment and print job generations. The parts were then printed on a stainless-steel building plate (stainless steel, $123 \times 123 \times 25 \mathrm{~mm}^{3}$ ). The LPBF was monitored using a layer control system installed in the $\mathrm{SLM}^{\circledR} 125$ printer. Pictures of the ongoing printing were captured using a 12-megapixel CCD camera.

\subsection{Characterization of $\mathrm{Cu} / \mathrm{D}$ composites.}


The Archimedes method (Mettler Toledo AT201) was used to measure the real density of the samples. The relative density was calculated by dividing the real density by the theoretical one (D Theoretical $=8.63 \mathrm{~g} / \mathrm{cm}^{3}$ ). The apparent density was measured using the open-source ImageJ software on SEM micrographs [29]. The microstructure of printed parts was observed using an SEM (FEI Quanta $200 \mathrm{ESEM}^{\mathrm{TM}}$ ). The cross-sectional view of the samples was analyzed by cutting and polishing the $\mathrm{Cu} / \mathrm{D}$ composites. The average surface roughness was measured using an optical surface profiler (Zygo NewView 8000). The sample's thermal diffusivity (TD) was measured using an advanced photothermal experiment described elsewhere [30]. The TD was carried out by measuring the temperature change at the rear surface when the front face was submitted to a heat flux with a Dirac comb waveform. The photothermal method did not require the sample surfaces to be coated with graphite layers to enhance the absorptivity and emissivity and thus led to more accurate thermal conductivity measurement. To estimate the in-plane and out-of-plane thermal properties, the experiment was performed within the samples' two directions. The TD was converted into TC using the following equation :

$$
k(T)=a(T) \times C_{p}(T) \times \rho(T),
$$

Where $k$ is the thermal conductivity (W/m.K), $a$ is the thermal diffusivity $\left(\mathrm{mm}^{2} / \mathrm{s}\right), \rho$ is the density, and $C_{p}$ is the heat capacity of the sample (J/Kg.K). The effective $\mathrm{Cp}$ is calculated from that of D, $\mathrm{TiC}$, and $\mathrm{Cu}$ that were 630, 190, and $392 \mathrm{~J} / \mathrm{Kg} . \mathrm{K}$, respectively [31]. More information on the measurement can be found in supplementary information.

\section{Results and discussion}

\subsection{Conventional laser powder bed fusion of Cu/D composites.}


Copper and D are known as a nonreactive system with a lack of chemical affinity [32,33]. Several studies have indicated that the $\mathrm{Cu}-\mathrm{D}$ interfacial resistance is the main parameter that governs the resulting TC [31]. Therefore, creating interphase between both components can allow a proper thermal transfer from the matrix to the reinforcement $[4,34,35]$. Hence, in this study, D particles were coated with a graded titanium dioxide - titanium carbide $\left(\mathrm{TiO}_{2}-\mathrm{TiC}\right)$ coating to enhance $\mathrm{Cu}$ 's wettability on D (Fig. S1a - b) [28]. A 5 vol.\% coated -D was then mixed with a pure Cu powder, as shown in Fig. S1 c - f. In conventional LPBF, a 3D object is printed layer upon layer by repeating a three-step process, as illustrated in Fig. S2: 1) deposition of a thin powder layer, 2) laser melting, and 3) lowering the build plate. The three-step process is referred to as the singlemelting strategy. The typical parameters to print $\mathrm{Cu}$ as reported in the literature, are a laser power (P) ranging from 200 to $1000 \mathrm{~W}$, a scan speed (s) between 200 and $1000 \mathrm{~mm} / \mathrm{s}$, a layer thickness (LT) from 0.03 to $0.05 \mathrm{~mm}$, and a hatch distance (h) from 0.05 to $0.12 \mathrm{~mm}$ [20,22,23,36]. Initially, the following parameters were investigated to print $\mathrm{Cu} / \mathrm{D}$ composites: $\mathrm{s}=100$ to $600 \mathrm{~mm} / \mathrm{s}$ and $\mathrm{h}$ $=0.03$ to $0.12 \mathrm{~mm}$. The laser power and layer thickness were fixed at $400 \mathrm{~W}$ and $0.03 \mathrm{~mm}$, respectively, for all experiments.

The ongoing printing of $\mathrm{Cu} / \mathrm{D}$ composites using a single-melting strategy is presented in Fig. 1a. In this image, a significant number of spatter ejections appeared during the laser/Cu+D powder interactions (Fig. 1b), accompanied by a dense metal vapor. Spatter ejection is a common phenomenon in LPBF and is often categorized into two types. When the laser strikes the powder bed, a spheroidal molten pool is created within a few microseconds [37]. Quickly, a metal vapor emerges above the molten pool, inducing a recoil pressure onto the pool surface. Meanwhile, inside the liquid, a thermal gradient rapidly develops, producing a flow of molten metal from the hot area to the coldest one, known as the Marangoni effect. Both effects caused particle ejection, called 
recoil-induced ejection, as illustrated in Fig. 1c [38]. In the meantime, a denudation zone was created on the molten track's sides, where powders can be swept under the flow of the metal vapor and the gas shield. This type of particle ejections is called entrainment particle, as illustrated in Fig. 1c [39]. Intuitively, micrometric particles altered the molten pool rheology, surface tension, and metal vapor density, as has been reported [7,40,41]. Also, a pronounced spattering phenomenon was observed when 5 vol.\% coated -D was mixed with $\mathrm{Cu}$ compared to a pure $\mathrm{Cu}$ bed situation (Fig. S3a), thus confirming the negative effect of the coated -D on the molten pool.
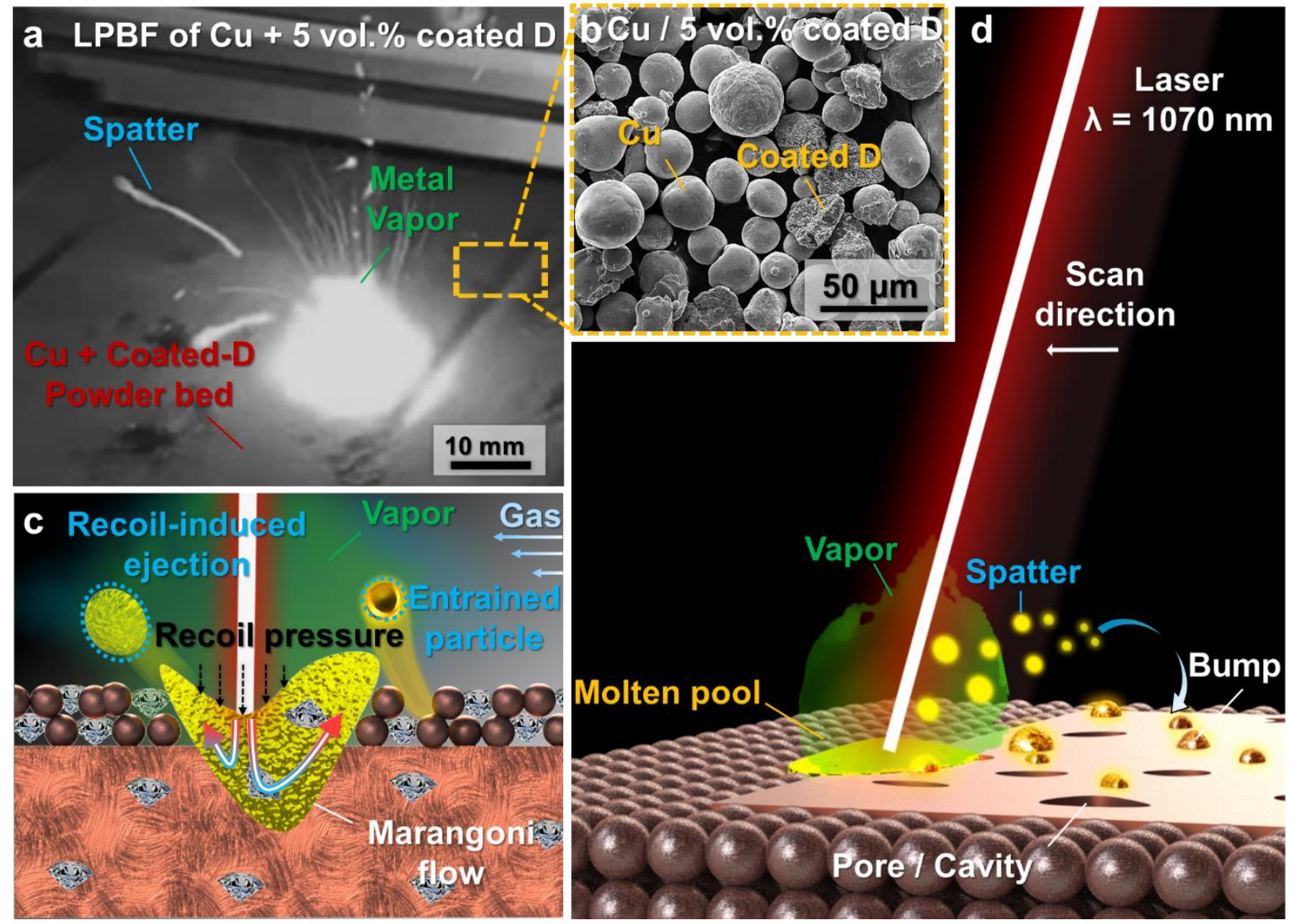

Fig. 1. Spatter ejection phenomenon during the $\mathrm{LBPF}$ of $\mathrm{Cu} / \mathrm{D}$ composite materials. (a) Optical photography of spatter ejection on $\mathrm{Cu}+$ coated $-\mathrm{D}$ powder bed, (b) SEM micrographs of the $\mathrm{Cu}+$ coated -D powder bed, (c) schematic illustration of spatter ejection phenomenon in LPBF, and (d) illustration of the spatter effect on the printing part. 
After ejection, the hot particles fall back into the powder bed, cool down, and partially fuse with the solid material (Fig. 1d). Then, during the deposition of a subsequent layer, the solidified particles create bumps, pores, and cavities on the part. Figs. 2a - c display the surface of $\mathrm{Cu} / \mathrm{D}$ composites printed with low, moderate, and high energy densities of 278,555 , and $1111 \mathrm{~J} / \mathrm{mm}^{3}$, respectively. As can be observed, the samples appear porous with large cavities and bumps. Several studies showed that laser power and scan speed are two key parameters that affect the number and size of spatters at constant layer thickness, pressure, and gas flow [38]. It is commonly accepted that a fast scan speed lowers the molten pool temperature, vapor pressure, and decreases the denudation zone, limiting the spatter ejection. However, all samples printed with a scan speed between 100 to $450 \mathrm{~mm} / \mathrm{s}$, were porous, as can be noted on the two-dimensional (2D) map in Fig. 2d $-\mathbf{e}$ and Fig. S4 with a relative density ranging from 67 to $90 \%$, depending on the energy density (Fig. 2f).

Furthermore, the energy required to $3 \mathrm{D}$ print $\mathrm{Cu} / \mathrm{D}$ composites appears more substantial than that for pure $\mathrm{Cu}$, where an energy density of $275 \mathrm{~J} / \mathrm{mm}^{3}$ led to a dense material (95\%), as shown in Fig. $2 \mathbf{f}$ [23]. The higher energy density required to print $\mathrm{Cu} / \mathrm{D}$ composites compared to pure $\mathrm{Cu}$ is caused by solid coated -D into the molten $\mathrm{Cu}$ pool. The solid particles increased the molten metal viscosity and limited its ability to flow and fuse [12]. Y. Ma et al. reported the same phenomenon when they attempted to print aluminum-silicon /diamond $\left(\mathrm{Al}_{12} \mathrm{Si} / \mathrm{D}\right)$ composites [9]. Alongside, the high energy density required to 3D laser print $\mathrm{Cu} / \mathrm{D}$ generates critical back reflection of the laser beam because of the low Cu's optical absorption in the near-IR domain (i.e., $\lambda=1070 \mathrm{~nm}$ ) [42]. It was noticed that when setting an energy density above $1000 \mathrm{~J} / \mathrm{mm}^{3}$ (i.e., low scan speed < $200 \mathrm{~mm} / \mathrm{s}$ ), more than $10 \mathrm{~W}$ is back-reflected into the laser, thus shutting it down. Consequently, a scan speed limit of $200 \mathrm{~mm} / \mathrm{s}$ must be set to prevent damage to the laser optics and to the laser 
itself. Hence, the maximum relative density which can be reached using a single-melting is about $88 \%$. As a result, the $\mathrm{LPBF}$ of $\mathrm{Cu} / \mathrm{D}$ composites raises several issues. The micrometric coated -D induces spattering, and $\mathrm{Cu}$ reflectivity in the IR domain limits the scan speed to $200 \mathrm{~mm} / \mathrm{s}$.
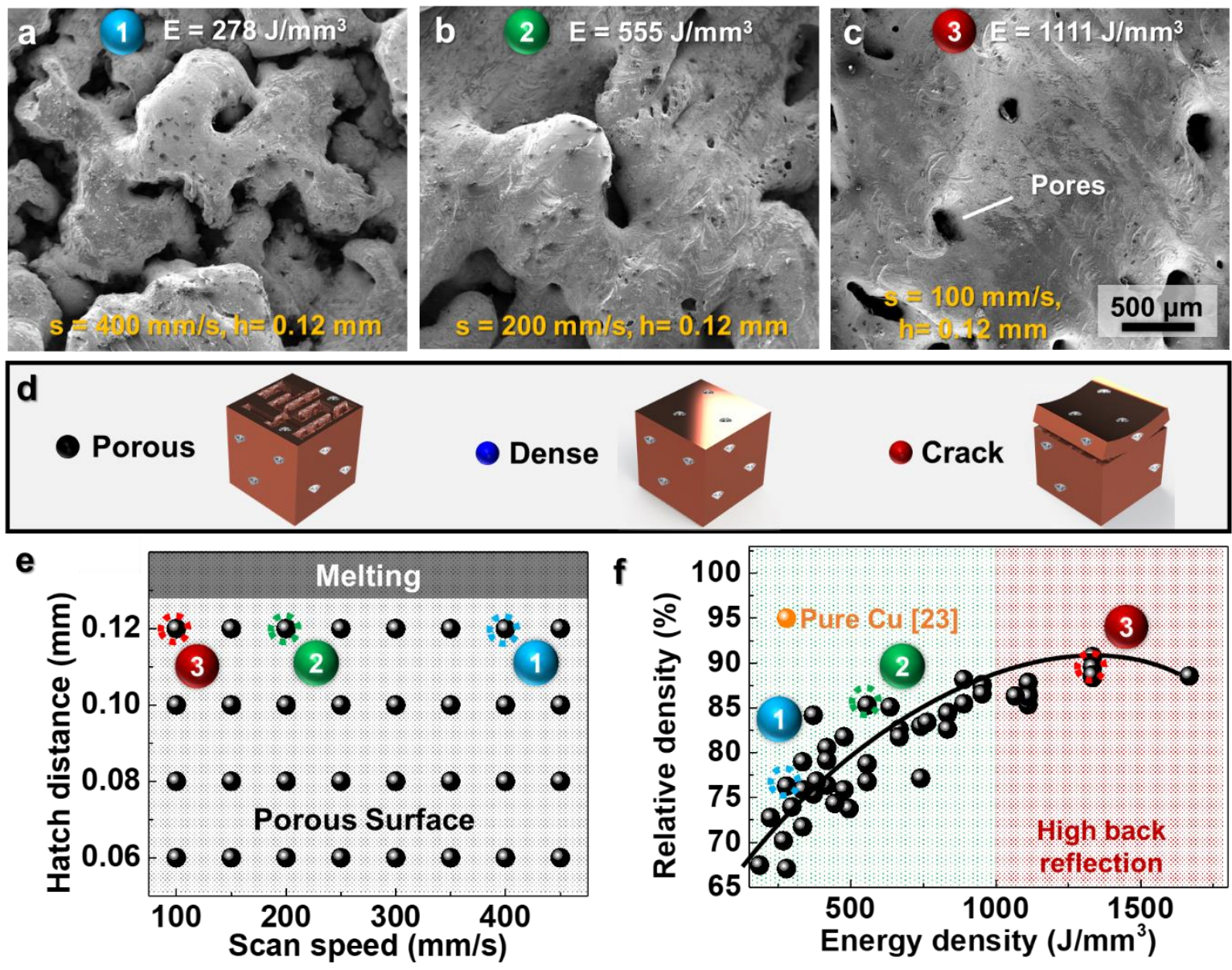

Fig. 2. Microstructure, quality, and relative density of $\mathrm{Cu} / \mathrm{D}$ composite materials printed using the conventional LPBF (i.e., single -melting strategy). SEM micrographs of $\mathrm{Cu} / \mathrm{D}$ surfaces printed with an energy density of (a) 333, (b) 533, and (c) $1111 \mathrm{~J} / \mathrm{mm}^{3}$. (d) illustration of parts' quality, (e) 2D map of the parts' quality as a function of the laser scan speed and hatch distance using the melting strategy, and (f) $\mathrm{Cu} / \mathrm{D}$ relative density $v s$. energy density. 


\subsection{Effect of printing strategies on density, quality, and microstructure of $\mathrm{Cu} / \mathrm{D}$ materials.}

To overcome these limitations, a recoating and remelting strategies were implemented in the LPBF. The recoating strategy aims to fill the pores by repassing the recoater on the same layer and shining the laser a second time. It involved a five-step process, as illustrated in Fig. S5: 1) deposition of a thin powder layer, 2) laser melting, 3) redeposition of thin powder layer, 4) laser melting, and 5) lowering the build plate. On the contrary, the remelting strategy has for objective to suppress printing defects, fill pores, and smoothens the surface by shining the laser twice on the same layer. This approach included a four-step process, as shown in Fig. S6: 1) deposition of a thin powder layer, 2) laser melting, 3) laser remelting, and 4) lowering the build plate. Metal matrix composites were then printed with different strategies and printing parameters. They were qualitatively categorized into porous, dense, and cracked, represented by the black, blue, and red circles in Fig. 2d. Photographs of the composites printed are included in Fig. S7 and S8.

The process map using the recoating strategy is shown in Fig 3a. As can be noted, fast scan speeds and large hatch distances led to porous surfaces. In contrast, slower speeds and smaller hatch distances (i.e., high energy density) generated cracked samples as a result of critical thermal gradients [43]. The same tendency was observed when the remelting strategy was used to print $\mathrm{Cu} / \mathrm{D}$ composite materials; but a small process window was found for scan speeds of 200, 250, 300 , and $350 \mathrm{~mm} / \mathrm{s}$ with hatch distances of $0.12,0.1,0.8$, and $0.6 \mathrm{~mm}$, respectively (Fig. 3b).

The relative density of the $\mathrm{Cu} / \mathrm{D}$ composite as a function of the energy density is shown in Fig. 3c. The remelted MMC with an energy density ranging from 500 to $700 \mathrm{~J} / \mathrm{mm}^{3}$ were the densest with a relative density of $97 \%$. Next, the recoated $\mathrm{Cu} / \mathrm{D}$ composite had a relative density of $92 \%$, followed by the single melted sample with $88 \%$. In addition, Fig. 3d displays the $\mathrm{Cu} / \mathrm{D}$ composites' 
relative density printed at a fixed hatch distance and using different printing strategies and scan speeds. As can be noted, the sample relative density decreased with faster speeds, a consequence of an insufficient flow and fusing of $\mathrm{Cu}$. These observations imply that the scan speed must be sufficiently slow to have an adequate flow of the molten metal but must be fast enough to avoid critical back reflection $(<200 \mathrm{~mm} / \mathrm{s})$.

The high relative density achieved using the remelting strategies can be explained by different phenomena during the printing. Layer thickness is a crucial parameter in spatter generation, as demonstrated by C. Qiu et al. [44]. They showed that when the layer thickness increased from 20 to $100 \mu \mathrm{m}$, the spatter and metal vapor increased and induced large pores, discontinuous laser tracks, and cavities on sample surfaces. Surface maps and average surface roughness (Ra) of printed Cu-D composites with different printing strategies are presented in Fig. S9. It is noticed that the $\mathrm{Cu} / \mathrm{D}$ composites printed with a single melting and recoating strategies have numerous defects and are significantly rough with a $\mathrm{Ra}$ of 130 and $85 \mu \mathrm{m}$, respectively (Fig. S9a-b). Naturally, holes, pores, and bumps alter the layer thickness, affecting the pool dynamic, thus promoting spatter ejection. Also, a rough surface induces a laser focus shift and inhibits its ability to melt the powder accurately [45]. Both effects combined or separately, can explain the formation of porous microstructures with the single-melting or recoating strategy, as illustrated in Fig. 3e f.

In contrast, the remelting strategy produces smooth $(\mathrm{Ra}=25 \mu \mathrm{m})$ and dense samples in the process window, as shown in Fig. 3g and Fig. S9 c-d. Several studies have demonstrated that the remelting of each layer allows the suppression of printing defects, filling pores, and smoothing the surface, as shown in Fig. 3g. W. Yu et al. show that the remelting of printed AlSiMg alloys allows decreasing the surface roughness for 21 to $10 \mu \mathrm{m}$ [46]. E. Yasa et al. reported that shining the laser 
twice on a stainless steel layer improves the final material's surface finish from 12 to $1.5 \mu \mathrm{m}$ and reduces its porosity from $0.8 \%$ down to $0.04 \%$ [47]. R. Li. et al. demonstrated that a remelting approach allows to melt and incorporate printing defects into the printed layer [48]. Hence, the remelting appears to be beneficial to print metallic parts and certainly to print MMCs.
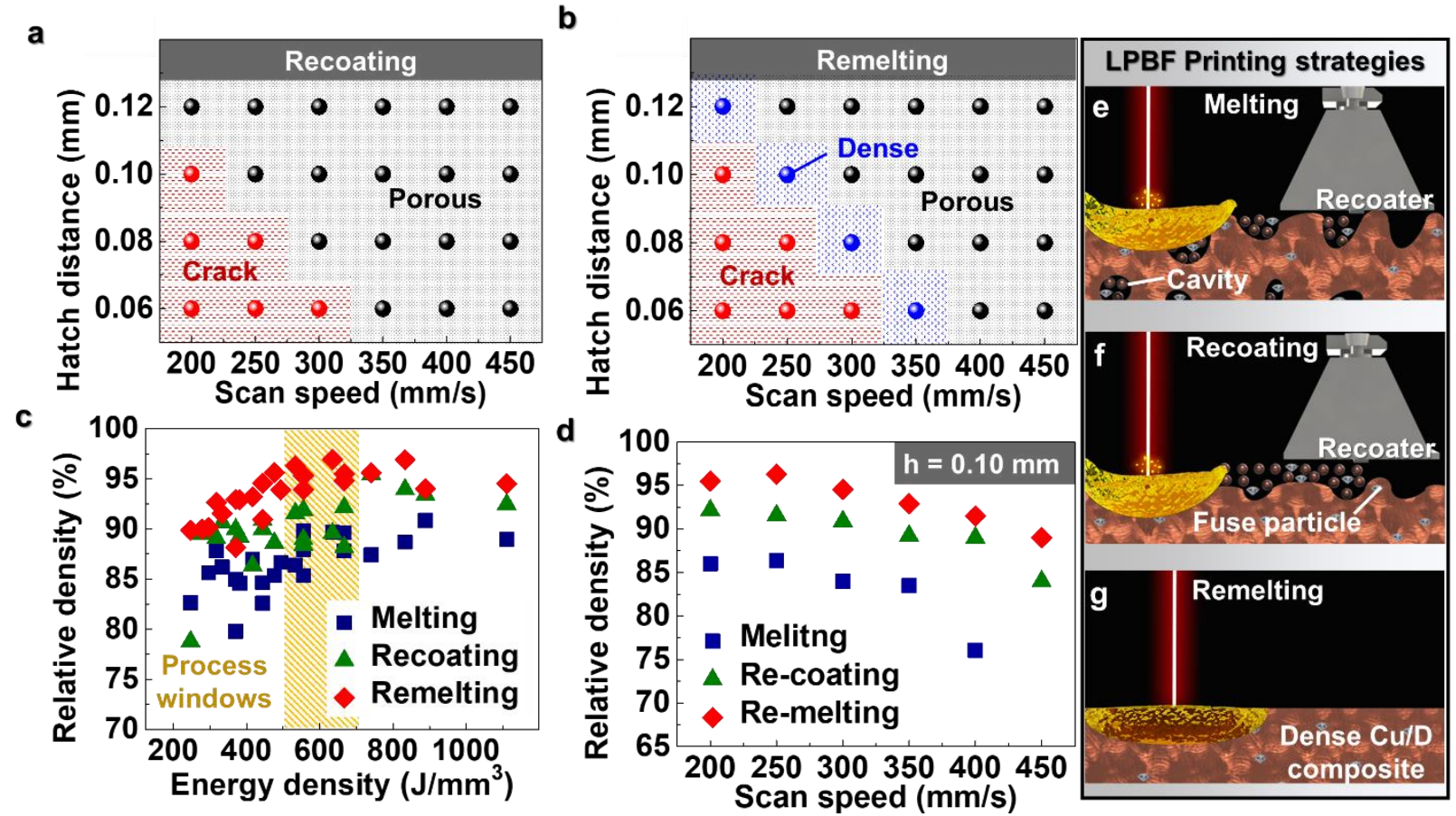

Fig. 3. Comparative study of $\mathrm{Cu} / \mathrm{D}$ composites quality and relative densities printed using the single-melting, recoating, and remelting strategies. (a) 2D map of the part quality as a function of laser scan speed and hatch distance using recoating, and (b) remelting strategies; (c) Cu/D relative density $v s$. energy density; (d) $\mathrm{Cu} / \mathrm{D}$ relative density as a function of scan speed ( $\mathrm{h}=0.10 \mathrm{~mm})$; and (e) illustration of $\mathrm{Cu} / \mathrm{D}$ composites surfaces when using the single-melting, (f) recoating, and (g) remelting strategies.

Furthermore, to get more insight into the influence of the printing strategies on the powder bed and composite qualities, in-situ monitoring of the LPBF was carried out using the layer control system (Fig. 4 a). Note that the images allowed observing only significant particles representing a 
small amount of the spatter ejection but were the most likely to have influenced the printing quality (Fig. S3). S. Ly et al. reported that the size of the recoil-induced particle ejections (i.e., molten pool) was larger than the raw powders, while entrainment particles had a similar size [39]. Hence, the large particles observed here may have originated from an instability of the molten pool induced by the coated -D. As can be seen in Fig. S10, the molten pools have a comparable size with the D particles (Fig. S1b) for all printing strategies. Note that the scan speed and hatch distance were fixed to $250 \mathrm{~mm} / \mathrm{s}$ and $0.10 \mathrm{~mm}$, respectively, for the rest of the study.

The powder-bed pictures after the coating of a new layer at different stages of the printing using the single-melting strategy are presented in Fig. $\mathbf{4 b}$. As can be seen at the beginning of the print (Layer 10), the powder bed was flat, uniform, and without defects. Next, when the number of layers increased (Layer 60), large white particles appeared on the bed surface. Later, they disappeared (Layer 110), and the printed part emerged, with particle-like features at the surface. The fading away of the large particles after 110 layers was due to their absorption inside the bed and incorporation into the printed part, causing the part's roughness $(\mathrm{Ra} \sim 130 \mu \mathrm{m})$. At the end of the print, the $\mathrm{Cu} / \mathrm{D}$ composite materials appear rough and porous $(\mathrm{d}=88 \%)$ as shown Fig. 4e. When using the recoating strategy, the bed was uniform at the beginning of the print; then, significant spatter appears when the LPBF went on, as displayed in Fig. 4c. The recoating filled some pores by redepositing powders and applying the laser a second time. Nonetheless, a more considerable amount of powder was deposited on each layer, leading to an increased number of spatter ejections. Finally, the part showed an improved surface $(\mathrm{Ra} \sim 85 \mu \mathrm{m})$; but the pores remained as observed in Fig. $4 \mathbf{e}(\mathrm{d}=92 \%)$. In contrast, only a few spatter particles were found on the powder bed with the remelting strategy (Fig. 4c), leading to 3D laser printing of smoother ( $\mathrm{Ra}$ $\sim 25 \mu \mathrm{m})$ and denser composite structures $(\mathrm{d}=97 \%)$ as presented in Fig $4 \mathbf{e}$. 


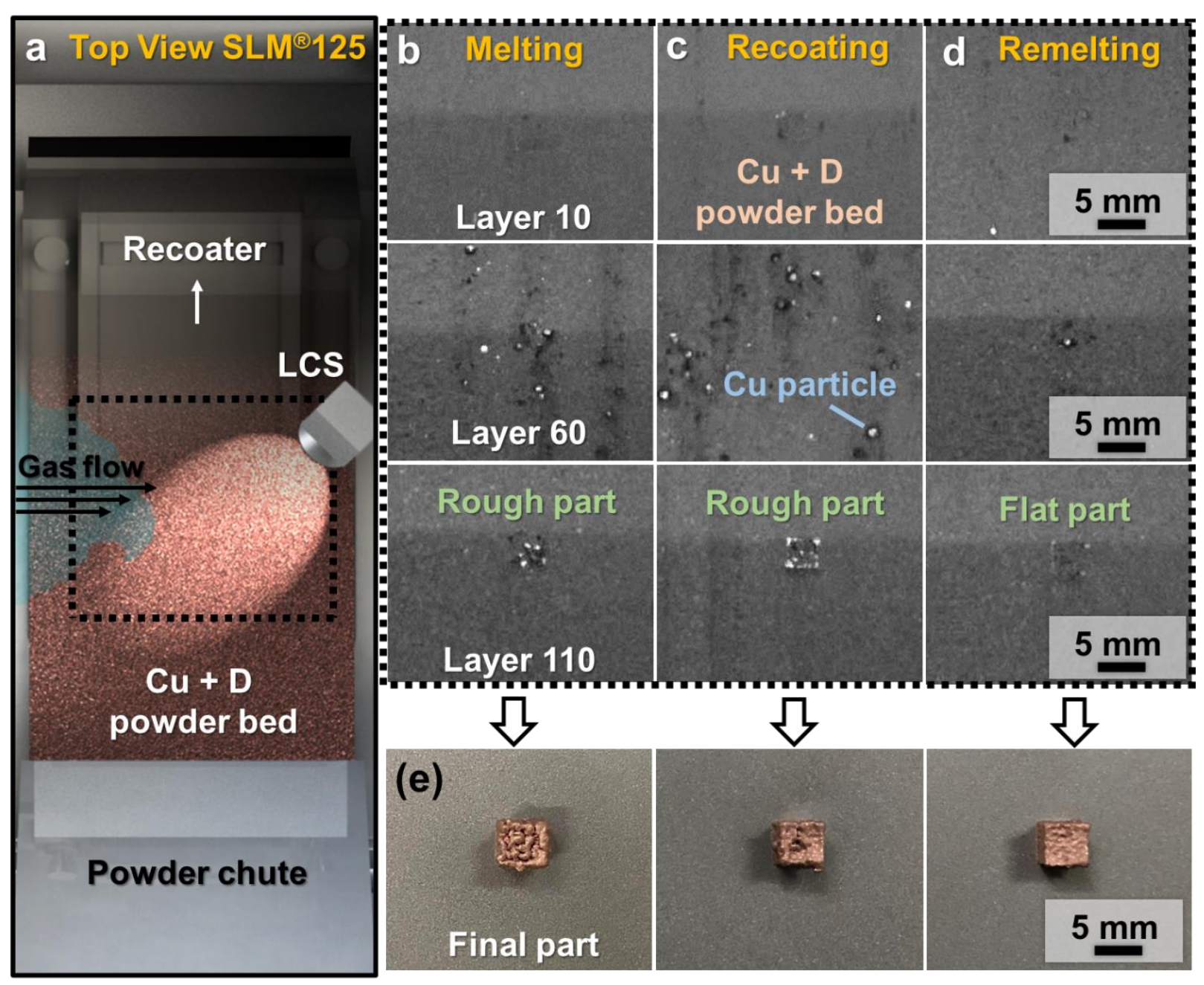

Fig. 4. Effect of the printing strategy on the powder-bed and composites qualities. (a) Illustration of the layer control system in the $\mathrm{SLM}^{\circledR} 125$ printer. (b) Images of the powder bed after coating a new layer using the melting, (c) recoating, and (d) remelting strategies. (e) photos of the printed part. The printing parameters were fixed to $\mathrm{s}=250 \mathrm{~mm} / \mathrm{s}, \mathrm{h}=0.1 \mathrm{~mm}, \mathrm{P}=400 \mathrm{~W}$, and $\mathrm{LT}=0.03$ $\mathrm{mm}$.

Next, the microstructures of the previously printed samples $(\mathrm{s}=250 \mathrm{~mm} / \mathrm{s}, \mathrm{h}=0.10 \mathrm{~mm})$ were studied along the building direction to further comprehend the role of the printing strategy on the layer-upon-layer manufacturing of $\mathrm{Cu} / \mathrm{D}$ composites (Fig. 5a). The microstructure of the $\mathrm{Cu} / \mathrm{D}$ composite printed using the single-melting strategy is presented in Fig. 5b. The sample shows 
pores, cavities with sizes up to $500 \mu \mathrm{m}$, and partially fused powder. The presence of these printing defects was expected, considering the previous observations. Undoubtedly, adding a new layer on a high defect $\mathrm{Cu} / \mathrm{D}$ surface led to uneven powder dispersion. Thus, the defects remained during the printing, contributing to the low-density microstructure formation with an apparent density of about $80 \%$. Fig. $5 \mathbf{c}$ shows the microstructure of the sample printed using the recoating strategy. The sample appeared denser compared to the single-melting approach with an apparent density of about $88 \%$, but pores remained with size up to $200 \mu \mathrm{m}$. As mentioned previously, the recoating approach allowed pores and cavities to be filled during the LPBF by adding a new powder layer and shining the laser a second time. Nevertheless, spatter ejection continued, adding defects to the composite material. Thus, a partially dense sample was obtained, as shown in the SEM micrographs. Fig. 5d displays the microstructure of the sample printed using the remelting strategy. The sample cross-section and surface are dense with an apparent density of about $98 \%$, and only a few pores can be observed with size up to $50 \mu \mathrm{m}$. These observations confirmed the advantages of using the remelting printing strategy to manufacture dense microcomposites. 

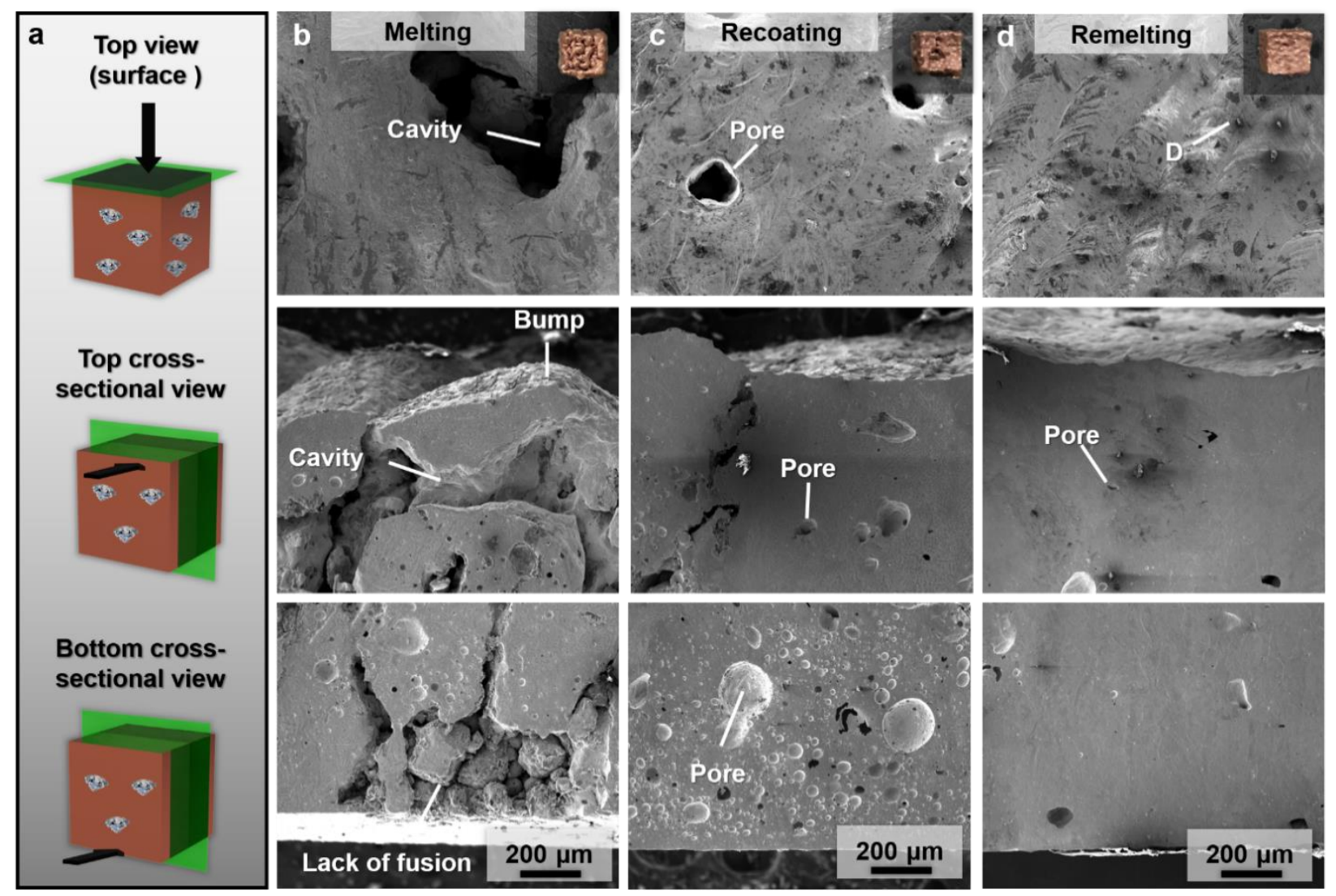

Fig. 5. Microstructural study of $\mathrm{Cu} / \mathrm{D}$ composites printed with different printing strategies. (a) Illustration of the $\mathrm{Cu} / \mathrm{D}$ composite areas observed. (b) SEM micrographs of the part printed using a scan speed of $250 \mathrm{~mm} / \mathrm{s}$ and a hatch distance of $0.10 \mathrm{~mm}$ using the single-melting, (c) recoating, and (d) remelting strategies.

\subsubsection{D printing of complex $\mathrm{Cu} / \mathrm{D}$ composites for thermal management applications.}

The TC of the as-built $\mathrm{Cu} / \mathrm{D}$ composites printed with the different printing strategies $(\mathrm{s}=250 \mathrm{~mm} / \mathrm{s}$ and $h=0.10 \mathrm{~mm}$ ) was measured using the photothermal method and is presented in Fig. 6a. More information on the TC measurement can be found in Fig S9. The single melted Cu/D composite had a low TC of $236 \mathrm{~W} / \mathrm{m} . \mathrm{K}$. This result was expected considering its low relative density. Next, the samples printed using the recoating strategy showed improved thermal performance with a TC of $327 \mathrm{~W} / \mathrm{m}$. K. Finally, the MMC printed using the remelting strategy showed a high TC of 349 
$\mathrm{W} / \mathrm{m} . \mathrm{K}$. These measurements match the previous density and microstructural analyses. In addition, it is worth mentioning that the $\mathrm{TC}$ of the as-built remelted $\mathrm{Cu} / \mathrm{D}$ composite was higher than the one reported for as-built pure $\mathrm{Cu}(336 \mathrm{~W} / \mathrm{m} . \mathrm{K})$ and the as-built $\mathrm{Cu}-\mathrm{Cr}$ alloy $(112 \mathrm{~W} / \mathrm{m} . \mathrm{K})$, both by LPBF [20,25].

Copper/D composite materials are commonly referred to as the next generation of thermal management materials for microelectronic applications (Fig. 6b). Heat sinks require a high surface area to enhance heat dissipation, to be realized by intricate designs. However, sophisticated designs are challenging to achieve on D-based materials due to the presence of D particles [5]. On the other hand, $\mathrm{Cu}$ has a high density $\left(8.93 \mathrm{~g} / \mathrm{cm}^{3}\right)$, limiting its thermal management applications as compared to aluminum $\left(\mathrm{Al}, 2.7 \mathrm{~g} / \mathrm{cm}^{3}\right)$, which is often preferred for its lightweight. Nevertheless, LPBF offers the possibility of fabricating efficient and lightweight $\mathrm{Cu} / \mathrm{D}$ heat sinks by forming intricate and architectural objects. In a recent report, M. Wong et al. showed that the heat dissipation of a D-structure made of $\mathrm{Al}$ alloys was $60 \%$ more efficient than an array heat sink while being lightweight and strong [49-51]. In the same manner, honeycomb structures are wellestablished as effective and lightweight heat dissipators [52]. Therefore, combining these shapes with the excellent thermal properties of $\mathrm{Cu} / \mathrm{D}$ materials could improve their thermal performance by increasing the surface area while enhancing their attractiveness by lowering the weight. Fig. 6c shows a photograph and SEM micrographs of a dense and highly complex D-structure with dimensions of about $3.5 \times 3.5 \times 1.5 \mathrm{~cm}^{3}$ manufactured using the optimized printing parameters (i.e., remelting, $\mathrm{s}=250 \mathrm{~mm} / \mathrm{s}, \mathrm{h}=0.1 \mathrm{~mm}$ ). Note that the structure was sandblasted to remove the residual particles on sidewalls. Next, three honeycomb objects were additively manufactured with filling percentages ranging from 40 to $60 \%$, as presented in Fig. 6d. 

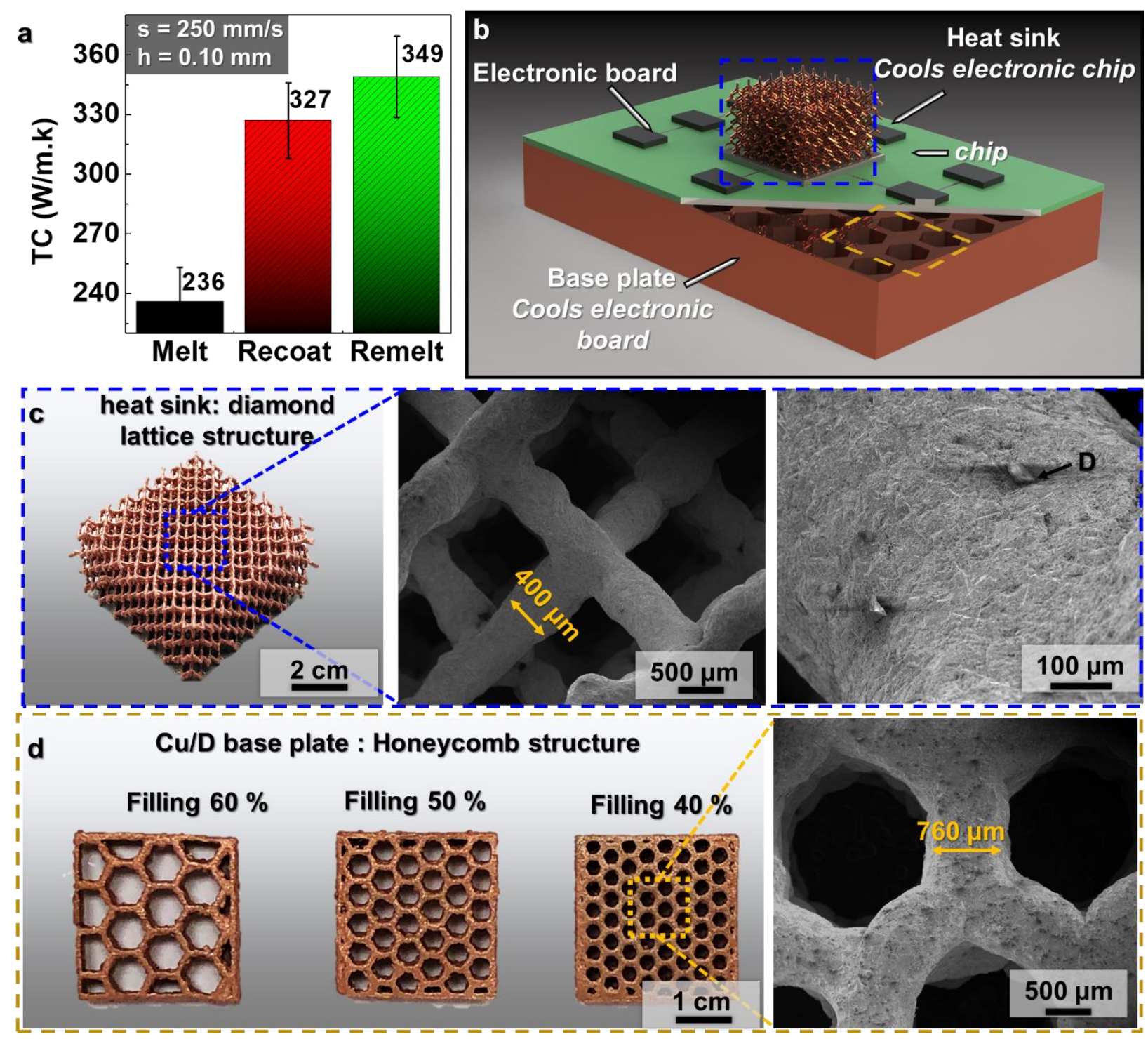

Fig. 6. Thermal performance and utility of complex $\mathrm{Cu} / \mathrm{D}$ structures. (a) Thermal conductivity of $\mathrm{Cu} / \mathrm{D}$ composites printed with the melting, recoating, and remelting strategies at $\mathrm{s}=250 \mathrm{~mm} / \mathrm{s}$ and $\mathrm{h}=0.10 \mathrm{~mm}$. (b) illustration of $\mathrm{Cu} / \mathrm{D}$ composites for microelectronic applications, (c) photograph and SEM micrographs of a D-lattice structure, and (d) honeycomb structures. 


\section{Conclusion}

In summary, by adding new printing steps in LPBF (i.e., remelting), we demonstrated the 3D laser printing of dense (97\%), complex, and high TC (349 W/m.K) Cu/D composites. Studying the effect of the single-melting, recoating, and remelting strategies on the powder-bed quality and composite characteristics shows the prospective benefits of adding new steps to 3D laser printing of high-quality microcomposites. We expect that developing new printing strategies for LPBF could open new avenues to laser 3D print a broad range of MMCs that is not possible today. Thereby, unleashing their full potential, as demonstrated on a $\mathrm{Cu} / \mathrm{D}$ composite, for thermal management applications. In particular, the ability to design complex $\mathrm{Cu} / \mathrm{D}$ parts as the most efficient thermal structures could significantly enhance their thermal performance, lower their density, and thus increase their attractiveness for advanced thermal management applications.

\section{Data Availability}

Data generated during or analyzed during the current study are included in this published article and its Supplementary Information file.

\section{AUTHOR INFORMATION}

\section{Corresponding Authors}

*Jean-François Silvain : jean-francois.silvain@icmcb.cnrs.fr; Yong Feng Lu :ylu2@unl.edu.

\section{Author Contributions}

† Dr. Loic Constantin, Mrs. Nada Kraiem, and Mr. Zhipeng Wu contributed equally to this work. All authors approved the final version. 


\section{Acknowledgments}

The authors are grateful for the financial support provided by the National Science Foundation

(CMMI 1825608) and the Nebraska Center for Energy Sciences Research (NCESR). The authors would like to thank Jamie Eske for her help on the English editing.

\section{References}

[1] S.M.H. Hojjatzadeh, N.D. Parab, W. Yan, Q. Guo, L. Xiong, C. Zhao, M. Qu, L.I. Escano, X. Xiao, K. Fezzaa, W. Everhart, T. Sun, L. Chen, Pore elimination mechanisms during 3D printing of metals, Nat Commun. 10 (2019) 1-8. https://doi.org/10.1038/s41467-019-10973-9.

[2] K.K. Chawla, Metal Matrix Composites, in: K.K. Chawla (Ed.), Composite Materials: Science and Engineering, Springer, New York, NY, 2012: pp. 197-248. https://doi.org/10.1007/978-0-38774365-3_6.

[3] D.K. Sharma, D. Mahant, G. Upadhyay, Manufacturing of metal matrix composites: A state of review, Materials Today: Proceedings. 26 (2020) 506-519. https://doi.org/10.1016/j.matpr.2019.12.128.

[4] J.-F. Silvain, J.-M. Heintz, A. Veillere, L. Constantin, Y. Lu, A review of processing of Cu/C base plate composites for interfacial control and improved properties, Int. J. Extrem. Manuf. (2019). https://doi.org/10.1088/2631-7990/ab61c5.

[5] R. Neugebauer, B. Müller, M. Gebauer, T. Töppel, Additive manufacturing boosts efficiency of heat transfer components, Assembly Automation. (2011). https://doi.org/10.1108/01445151111172925.

[6] L. Constantin, L. Fan, M. Pontoreau, F. Wang, B. Cui, J.-L. Battaglia, J.-F. Silvain, Y.F. Lu, Additive Manufacturing of Copper/Diamond Composites for Thermal Management Applications, Manufacturing Letters. (2020). https://doi.org/10.1016/j.mfglet.2020.03.014.

[7] L. Xi, D. Gu, K. Lin, S. Guo, Y. Liu, Y. Li, M. Guo, Effect of ceramic particle size on densification behavior, microstructure formation, and performance of TiB2-reinforced Al-based composites prepared by selective laser melting, Journal of Materials Research. 35 (2020) 559-570. https://doi.org/10.1557/jmr.2019.392.

[8] A. Simchi, H. Pohl, Direct laser sintering of iron-graphite powder mixture, Materials Science and Engineering: A. 383 (2004) 191-200. https://doi.org/10.1016/j.msea.2004.05.070.

[9] Y. Ma, G. Ji, X.P. Li, C.Y. Chen, Z.Q. Tan, A. Addad, Z.Q. Li, T.B. Sercombe, J.P. Kruth, On the study of tailorable interface structure in a diamond/Al12Si composite processed by selective laser melting, Materialia. 5 (2019) 100242. https://doi.org/10.1016/j.mtla.2019.100242.

[10] R. Li, Y. Shi, J. Liu, Z. Xie, Z. Wang, Selective laser melting W-10 wt.\% Cu composite powders, Int J Adv Manuf Technol. 48 (2010) 597-605. https://doi.org/10.1007/s00170-009-2304-4.

[11] A. Aversa, G. Marchese, M. Lorusso, F. Calignano, S. Biamino, E.P. Ambrosio, D. Manfredi, P. Fino, M. Lombardi, M. Pavese, Microstructural and Mechanical Characterization of Aluminum Matrix Composites Produced by Laser Powder Bed Fusion, Advanced Engineering Materials. 19 (2017) 1700180. https://doi.org/10.1002/adem.201700180.

[12] D. Gu, Y.-C. Hagedorn, W. Meiners, K. Wissenbach, R. Poprawe, Nanocrystalline TiC reinforced Ti matrix bulk-form nanocomposites by Selective Laser Melting (SLM): Densification, growth 
mechanism and wear behavior, Composites Science and Technology. 71 (2011) 1612-1620. https://doi.org/10.1016/j.compscitech.2011.07.010.

[13] C. Gao, Z. Wang, Z. Xiao, D. You, K. Wong, A.H. Akbarzadeh, Selective laser melting of TiN nanoparticle-reinforced AISi10Mg composite: Microstructural, interfacial, and mechanical properties, Journal of Materials Processing Technology. 281 (2020) 116618. https://doi.org/10.1016/j.jmatprotec.2020.116618.

[14] D. Gu, H. Wang, D. Dai, F. Chang, W. Meiners, Y.-C. Hagedorn, K. Wissenbach, I. Kelbassa, R. Poprawe, Densification behavior, microstructure evolution, and wear property of TiC nanoparticle reinforced AlSi10Mg bulk-form nanocomposites prepared by selective laser melting, Journal of Laser Applications. 27 (2014) S17003. https://doi.org/10.2351/1.4870877.

[15] C.C. Leong, L. Lu, J.Y.H. Fuh, Y.S. Wong, In-situ formation of copper matrix composites by laser sintering, Materials Science and Engineering: A. 338 (2002) 81-88. https://doi.org/10.1016/S09215093(02)00050-3.

[16] A. Slocombe, L. Li, Selective laser sintering of TiC-Al2O3 composite with self-propagating hightemperature synthesis, Journal of Materials Processing Technology. 118 (2001) 173-178. https://doi.org/10.1016/S0924-0136(01)00905-0.

[17] S. Kumar, J.-P. Kruth, Composites by rapid prototyping technology, Materials \& Design. 31 (2010) 850-856. https://doi.org/10.1016/j.matdes.2009.07.045.

[18] B. AlMangour, D. Grzesiak, J.-M. Yang, In-situ formation of novel TiC-particle-reinforced 316L stainless steel bulk-form composites by selective laser melting, Journal of Alloys and Compounds. 706 (2017) 409-418. https://doi.org/10.1016/j.jallcom.2017.01.149.

[19] V. Lindström, O. Liashenko, K. Zweiacker, S. Derevianko, V. Morozovych, Y. Lyashenko, C. Leinenbach, Laser Powder Bed Fusion of Metal Coated Copper Powders, Materials. 13 (2020) 3493. https://doi.org/10.3390/ma13163493.

[20] S.D. Jadhav, S. Dadbakhsh, L. Goossens, J.-P. Kruth, J. Van Humbeeck, K. Vanmeensel, Influence of selective laser melting process parameters on texture evolution in pure copper, Journal of Materials Processing Technology. 270 (2019) 47-58. https://doi.org/10.1016/j.jmatprotec.2019.02.022.

[21] S.D. Jadhav, S. Dadbakhsh, J. Vleugels, J. Hofkens, P. Van Puyvelde, S. Yang, J.-P. Kruth, J. Van Humbeeck, K. Vanmeensel, Influence of Carbon Nanoparticle Addition (and Impurities) on Selective Laser Melting of Pure Copper, Materials (Basel). 12 (2019). https://doi.org/10.3390/ma12152469.

[22] T.-T. Ikeshoji, K. Nakamura, M. Yonehara, K. Imai, H. Kyogoku, Selective Laser Melting of Pure Copper, JOM. 70 (2018) 396-400. https://doi.org/10.1007/s11837-017-2695-x.

[23] L. Constantin, Z. Wu, N. Li, L. Fan, J.-F. Silvain, Y.F. Lu, Laser 3D printing of complex copper structures, Additive Manufacturing. 35 (2020) 101268. https://doi.org/10.1016/j.addma.2020.101268.

[24] C. Silbernagel, L. Gargalis, I. Ashcroft, R. Hague, M. Galea, P. Dickens, Electrical resistivity of pure copper processed by medium-powered laser powder bed fusion additive manufacturing for use in electromagnetic applications, Additive Manufacturing. 29 (2019) 100831. https://doi.org/10.1016/j.addma.2019.100831.

[25] S.D. Jadhav, P.P. Dhekne, S. Dadbakhsh, J.-P. Kruth, J. Van Humbeeck, K. Vanmeensel, Surface Modified Copper Alloy Powder for Reliable Laser-based Additive Manufacturing, Additive Manufacturing. 35 (2020) 101418. https://doi.org/10.1016/j.addma.2020.101418.

[26] S. Uchida, T. Kimura, T. Nakamoto, T. Ozaki, T. Miki, M. Takemura, Y. Oka, R. Tsubota, Microstructures and electrical and mechanical properties of $\mathrm{Cu}-\mathrm{Cr}$ alloys fabricated by selective laser melting, Materials \& Design. 175 (2019) 107815. https://doi.org/10.1016/j.matdes.2019.107815. 
[27] S. Zhang, H. Zhu, L. Zhang, W. Zhang, H. Yang, X. Zeng, Microstructure and properties of high strength and high conductivity $\mathrm{Cu}-\mathrm{Cr}$ alloy components fabricated by high power selective laser melting, Materials Letters. 237 (2019) 306-309. https://doi.org/10.1016/j.matlet.2018.11.118.

[28] L. Constantin, L. Fan, Q. Zou, B. Thomas, J. Roger, J.-M. Heinz, C. Debiemme-Chouvy, B. Mortainge, Y.F. Lu, J.-F. Silvain, Design of tailored oxide-carbide coating on carbon fibers for a robust copper/carbon interphase, Carbon. (2019). https://doi.org/10.1016/j.carbon.2019.11.032.

[29] ImageJ, (n.d.). https://imagej.nih.gov/ij/ (accessed November 30, 2020).

[30] E. Ruffio, C. Pradere, A. Sommier, J.-C. Batsale, A. Kusiak, J.-L. Battaglia, Signal noise ratio improvement technique for bulk thermal diffusivity measurement, International Journal of Thermal Sciences. 129 (2018) 385-395. https://doi.org/10.1016/j.ijthermalsci.2018.03.011.

[31] C. Azina, I. Cornu, J.-F. Silvain, Y. Lu, J.-L. Battaglia, Effect of titanium and zirconium carbide interphases on the thermal conductivity and interfacial heat transfers in copper/diamond composite materials, AIP Advances. 9 (2019) 055315. https://doi.org/10.1063/1.5052307.

[32] G.A. López, E.J. Mittemeijer, The solubility of C in solid Cu, Scripta Materialia. 51 (2004) 1-5. https://doi.org/10.1016/j.scriptamat.2004.03.028.

[33] B. Kong, J. Ru, H. Zhang, T. Fan, Enhanced wetting and properties of carbon/carbon-Cu composites with $\mathrm{Cr} 3 \mathrm{C} 2$ coatings by $\mathrm{Cr}$-solution immersion method, Journal of Materials Science \& Technology. 34 (2018) 458-465. https://doi.org/10.1016/j.jmst.2017.01.028.

[34] Y. Zhang, H.L. Zhang, J.H. Wu, X.T. Wang, Enhanced thermal conductivity in copper matrix composites reinforced with titanium-coated diamond particles, Scripta Materialia. 65 (2011) 10971100. https://doi.org/10.1016/j.scriptamat.2011.09.028.

[35] T. Schubert, Ł. Ciupiński, W. Zieliński, A. Michalski, T. Weißgärber, B. Kieback, Interfacial characterization of $\mathrm{Cu}$ /diamond composites prepared by powder metallurgy for heat sink applications, Scripta Materialia. 58 (2008) 263-266. https://doi.org/10.1016/j.scriptamat.2007.10.011.

[36] M. Colopi, L. Caprio, A.G. Demir, B. Previtali, Selective laser melting of pure Cu with a $1 \mathrm{~kW}$ single mode fiber laser, Procedia CIRP. 74 (2018) 59-63. https://doi.org/10.1016/j.procir.2018.08.030.

[37] A.V. Gusarov, I. Yadroitsev, P. Bertrand, I. Smurov, Model of Radiation and Heat Transfer in LaserPowder Interaction Zone at Selective Laser Melting, J. Heat Transfer. 131 (2009). https://doi.org/10.1115/1.3109245.

[38] J. Yin, L. Yang, X. Yang, H. Zhu, D. Wang, L. Ke, Z. Wang, G. Wang, X. Zeng, High-power laser-matter interaction during laser powder bed fusion, Additive Manufacturing. 29 (2019) 100778. https://doi.org/10.1016/j.addma.2019.100778.

[39] S. Ly, A.M. Rubenchik, S.A. Khairallah, G. Guss, M.J. Matthews, Metal vapor micro-jet controls material redistribution in laser powder bed fusion additive manufacturing, Sci Rep. 7 (2017) 1-12. https://doi.org/10.1038/s41598-017-04237-z.

[40] R. Sitek, M. Szustecki, L. Zrodowski, B. Wysocki, J. Jaroszewicz, P. Wisniewski, J. Mizera, Analysis of Microstructure and Properties of a Ti-AIN Composite Produced by Selective Laser Melting, Materials. 13 (2020) 2218. https://doi.org/10.3390/ma13102218.

[41] Y. Li, D. Gu, H. Zhang, L. Xi, Effect of Trace Addition of Ceramic on Microstructure Development and Mechanical Properties of Selective Laser Melted AlSi10Mg Alloy, Chinese Journal of Mechanical Engineering. 33 (2020) 33. https://doi.org/10.1186/s10033-020-00448-0.

[42] A. Hess, R. Schuster, A. Heider, R. Weber, T. Graf, Continuous Wave Laser Welding of Copper with Combined Beams at Wavelengths of 1030nm and of 515nm, Physics Procedia. 12 (2011) 88-94. https://doi.org/10.1016/j.phpro.2011.03.012.

[43] M.F. Zaeh, G. Branner, Investigations on residual stresses and deformations in selective laser melting, Prod. Eng. Res. Devel. 4 (2010) 35-45. https://doi.org/10.1007/s11740-009-0192-y. 
[44] C. Qiu, C. Panwisawas, M. Ward, H.C. Basoalto, J.W. Brooks, M.M. Attallah, On the role of melt flow into the surface structure and porosity development during selective laser melting, Acta Materialia. 96 (2015) 72-79. https://doi.org/10.1016/j.actamat.2015.06.004.

[45] G.E. Bean, D.B. Witkin, T.D. McLouth, D.N. Patel, R.J. Zaldivar, Effect of laser focus shift on surface quality and density of Inconel 718 parts produced via selective laser melting, Additive Manufacturing. 22 (2018) 207-215. https://doi.org/10.1016/j.addma.2018.04.024.

[46] Influence of re-melting on surface roughness and porosity of AlSi10Mg parts fabricated by selective laser melting, Journal of Alloys and Compounds. 792 (2019) 574-581. https://doi.org/10.1016/j.jallcom.2019.04.017.

[47] E. Yasa, J.-P. Kruth, J. Deckers, Manufacturing by combining Selective Laser Melting and Selective Laser Erosion/laser re-melting, CIRP Annals. Manufacturing Technology. 60 (2011) 263-266. https://doi.org/10.1016/j.cirp.2011.03.063.

[48] R. Li, J. Liu, Y. Shi, L. Wang, W. Jiang, Balling behavior of stainless steel and nickel powder during selective laser melting process, Int J Adv Manuf Technol. 59 (2012) 1025-1035. https://doi.org/10.1007/s00170-011-3566-1.

[49] M. Wong, I. Owen, C.J. Sutcliffe, Pressure Loss and Heat Transfer Through Heat Sinks Produced by Selective Laser Melting, Heat Transfer Engineering. 30 (2009) 1068-1076. https://doi.org/10.1080/01457630902922228.

[50] F. Liu, D.Z. Zhang, P. Zhang, M. Zhao, S. Jafar, Mechanical Properties of Optimized Diamond Lattice Structure for Bone Scaffolds Fabricated via Selective Laser Melting, Materials. 11 (2018) 374. https://doi.org/10.3390/ma11030374.

[51] M. Leary, M. Mazur, J. Elambasseril, M. McMillan, T. Chirent, Y. Sun, M. Qian, M. Easton, M. Brandt, Selective laser melting (SLM) of AISi12Mg lattice structures, Materials \& Design. 98 (2016) 344-357. https://doi.org/10.1016/j.matdes.2016.02.127.

[52] S.K. Sahoo, M.K. Das, P. Rath, Application of TCE-PCM based heat sinks for cooling of electronic components: A review, Renewable and Sustainable Energy Reviews. 59 (2016) 550-582. https://doi.org/10.1016/j.rser.2015.12.238. 